\title{
The Impact of Utilizing Shared Electric Vehicles on The Energy, Environmental pollution and Transportation
}

\author{
Siamak Ahmadian ${ }^{1}$, Grzegorz Sierpiński ${ }^{2}$ \\ ${ }^{1}$ Iran Construction Engineering Organization \\ Sari - North ring way - Nezam Mohandesi Street, Mazandaran, IRAN \\ ${ }^{2}$ Silesian University of Technology, Faculty of Transport and Aviation Engineering, Department of Transport Systems, \\ Traffic Engineering and Logistics \\ Krasińskiego Str. 8, 40-019 Katowice, POLAND \\ grzegorz.sierpinski@polsl.pl
}

\section{Extended Abstract}

Rapid economic growth and urbanization have motivated economists and researchers to seek innovative solutions for the many challenges that accompany these trends. This can be observed in upcoming research in sustainable transportation services where potential solutions to urban mobility issues are being explored [1]. Electrification has widely been considered as a viable strategy for reducing oil dependency of road transportation. electric cars have zero tailpipe (or tank-to-wheel) emissions, there are upstream emissions from manufacturing the battery and from electricity generation. But analyses of full life cycle $\mathrm{CO} 2$ consistently show that on average battery electric vehicles emit less $\mathrm{CO} 2$ over their lifetime than diesel cars. A meta-analysis of 11 independent LCA studies done in recent years concludes that a battery electric car over its lifetime produces 50\% less $\mathrm{CO} 2$ emissions than an average car today [2]. Also, car sharing has shown to be an effective method in enhancing the environmental benefits that EVs could offer to the transport and health. Car sharing can significantly help reducing traffic congestion, fuel consumptions and $\mathrm{CO} 2$ emissions; hence, improving fuel economy problems. Therefore, the application of Shared Electric Vehicles (SEVs) could be considered as a viable strategy that can potentially improve mobility. this research will contribute to the field of SEVs by: Optimising EVs in the car-sharing scheme, Developing a programme for identifying the severity of emissions, Proposing novel methods for reducing the costs of daily commutation and Identifying the required share of EVs on the streets in order to attain a sustainable transportation. In this research, several parameters need to be evaluated in order to study the potential impacts of the introduction of SEVs on air pollution such as number of EVs on the street, their annual mileage and speed, and their emission factors. The above, along with energy consumption, would be processed using COPERT street level. The COPERT methodology is part of the EMEP/EEA Air Pollutant Emission Inventory Guidebook [3] for the calculation of air pollutant emissions and is consistent with the 2006 IPCC Guidelines [4] for the calculation of greenhouse gas emissions. The required research data for the aforementioned parameters could be partially obtained from the COPERT database, and the rest are to be collected through conducting a case study analysis on the EVs operating on the streets. With the above data in hand, specifications of various pollutants could be obtained from COPERT for a particular crowded street. The results will then be visualised in ArcGIS to identify the highly-polluted areas. Then, shared mobility could be modelled to investigate the change in the level of pollution in those crowded areas. This study aims to develop a pattern for the optimal use of SEVs, especially in large cities with high traffic density and population, to the extent that, It could be minimise the amount of air pollution, energy costs, and traffic congestion.

Keywords: electric vehicles, shared mobility, copert, $\mathrm{co}_{2}$ emission

\section{References}

[1] B. Brendel, S. Lichtenberg, B. Brauer, I. Nastjuk, Lutz M.Kolbe."Improving Electric Vehicle Utilisation in Car-Sharing: A Framework and Simulation of an E-Carsharing Vehicle Utilisation Management System" Transportation Research Part D, vol. 64, 230-245, 2018.

[2] P. Molina, E. Hurtado-Pérez, E. Peñalvo-López, M. C. Moros-Gómez, Assessing Transport Emissions Reduction while Increasing Electric Vehicles and Renewable Generation Levels. Institute for Energy Engineering, University of Valencia, Spain, 2020. 
[3] European Environment Agency [Online]. https://www.eea.europa.eu/publications/emep-eea-guidebook-2019.

[4] The Intergovernmental Panel on Climate Change [Online] https://www.ipcc.ch/report/2006-ipcc-guidelines-fornational-greenhouse-gas-inventories 